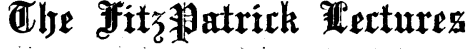 ox}

\section{THE HISTORY OF BRITISH MIDWIFERY (1650-1800)."}

\author{
Delivered before the Royal Colifge of Physiciang \\ of LONDON \\ $\mathrm{BY}$
}

HERBERT' R. SPENCER, M.D., F.R.C.P., EMERITUS PROFESSOR OF OBSTETRIC MEDICINE, UNIVERSITY COLLEGE, LONDON.

Dr. Herbert Spencer said that he had chosen the subject of "The history of British midwifery from 1650 to 1800 ," partly for the personal reason that it was one in which he was interested, and partly for the patriotic reason that it had been neglected by British writers. While admirable general histories of midwifery had been published by foreign writers, and exhaustive memoirs of individual British obstetricians had been produced, no detailed account of the work of British obstetricians of the period had hitherto appeared by a British author. The lectures were an attempt to remedy the deficiency.

British midwifery at the commencement of the period was not in a satisfactory condition. It was conducted mainly by women, of whom many were without the education, knowledge, or character requisite for its proper practice, and who maintained a determined opposition to male practitioners. The opposition was to some extent justifiable, inasmuch as, in the earlier part of the period, male practitioners made use of destructive instruments only, and had little experience of normal labour. The position of the male practitioner was long that of a consultant; at the birth of George IV, for example, the Queen was attended by Mrs. Draper, while William Hunter remained in waiting in ease his help should be required to deal with complications. The position began to change after the introduction of the forceps, which were coming into general use by the year 1733; the practice of midwifery was then rapidly taken up by male practitioners under the titles of men-midwives, mid-men, or andro-boethogynists. The opposition of the midwives during the transition period was naturally great, and, according to the fashion of the time, accompanied by much ponderons abuse, exemplified by such jhrases as "great-horse-god-mother of a he-midwife" the shaft levelled at Smellie by Mrs. Nihell; but by the end of the century the new situation was accepted and the opposition had died down.

\section{The Anatomy and Physiology of Pregnancy and} Labour.

The first original work on midwifery published by an Englishman was the chapter "De partu" in Harvey's De Generatione Animalium (1651), the English edition of which appeared in 1653-a work that justifies Aveling's description of Harvey as the Father of British Midwifery. The scientific part of Harvey's work consists in criticism, based on his own observation and experiments, of previous opinions concerning the anatomy and physiology of the foetus; the practical part gives evidence of extensive personal experience, and is in the main devoted to the recommendation of patient watchfulness and gentleness, in drdinary cases imitating Nature and in difficult cases, " where there is necessity for handiwork in the business," employing podalic version. Harvey was held in high esteem \$ an obstetric physician in his day, and it was he who iptroduced into British obstetric medicine the wide view, the scientific spirit, and the conservative practice which Have been its characteristics. His death occurred on June \$rd, 1657, and his body, "lapped in lead" and enclosed in the marble sarcophagus provided by the Royal College of Hhysicians, rests in the parish church of Hempstead in Fissex.

In the study of the anatomy of the pelvis, pregnant uterus, and foetus, the British obstetricians of the eighteenth century took a leading place, and the illustrated

* $\Lambda$ bstract of two lectures given on November 8th and 10th. The full text will be published shortly in a volume by Messrs. John Bale, Sons and Danielsson, Ltd. works of Hunter, Smellie, and Denman have not been surpassed by their successors. William Hunter, brother of John Hunter the celebrated anatomist, was born in 1718 at Long Calderwood, Lanark. His most valued contributions to obstetrics are anatomical, and he did a great service by insisting on the importance of morbid anatomy. His great work on the gravid uterus, the outcome of the examination of the bodies of pregnant women extending over twenty-four years, is the finest of the kind, and is illustrated with plates worthy to rank with those of Albinus. In addition to illustrations of the foetus, it contains dissections of the musculature of the uterus and illastrations of the decidua. Hunter was the first to describe the decidua reflexa and to show that the decidua was the lining of the uterus and was not derived from the orum. He also gave a description of the retroverted gravid uterus and of the symphysis pubis in pregnant women, and claimed the discovery of the placental circulation, a claim also made by his brother John, and the cause of the estrangement between the two which lasted till Hunter's death in 1783. As a practitioner his place is a modest one. He carried conservative treatment to a harmful extent, and failed to appreciate the value of the forceps, thinking it "a thousand pities it was ever invented," while others were using them at the time with success. He was a great, perhaps the greatest, anatomical teacher, and his large and remunerative practice provided him with funds for the promotion of his anatomical studies and teaching, which were the chief interest of his busy life, and to found the Windmill Street School of Anatomy, which he built and endowed. Hunter was, buried in St. James's Church,. Westminster, and left the use of his museum to Matthew Baillie with reversion to the University of Glasgow, where it is now preserved.

The credit of laying the foundations for the study of the mechanism of labour belongs to Sir Fielding Ould, born in Galway in 1710, appointed Master of the Rotunda Hospital in 1759 , and author of a Treatise of Midwifery (1742) which shows a distinct advance on the original obstetrical books which had previously appeared in English. He made a great advance in treating labour as a mechanical process, and in pointing out that the position of the foetal head at the brim and the movements of the foetus were due to the elliptical shape of the pelvis and of the shoulders and head of the foetus. He also clearly recognized for the first time that the head rotated and did not, during its passage, have its long axis at right angles to that of the shoulders, but "turned its chin towards one shoulder."

Ould was followed in the same line of thought by Smellie, whose work forms the basis of our knowledge of the mechanism of labour. Sinellie " endeavoured to reduce the art of midwifery to the principles of mechanism, ascertained the make, shape, and situation of the pelvis, together with the form and dimensions of the ehild's head, and explained the method of extraction from the rules of moving bodies in different directions." He studied labour in contracted pelves, and gives an admirable description and illustration of the rachitic pelvis. He also published a case of generally contracted pelvis associated with short stature, and of a pseudo-osteomalacic rachitic pelvis, and he recognized the transverse contraction of the pelvic qutlet in a case where "the. lower end of the ossa ischia were scarce three inches asunder." He gives measurements of the pelvis, was the first to measure the diagonal conjugate, and showed that the greatest diameter at the brim was the transverse. The measurement of the true conjugate we owe to Wallace Johnson, a pupil of Smellie's. Smellie made important improvements in forceps, devised the scissors-perforator and the curved and double articulated crochet, discovered the rotation of the head in occipitoposterior positions by means of his forceps, was the first to apply the forceps to deliver the after-coming head in breech presentations, and showed that the difficulty in contracted pelves occurs at the brim, and that in these cases the head usually lies with its long axis in the transverse diameter, with the sinciput deeply placed. Smellie's literary fame rests on his two great works, A Treatise on the Theory and Practice of Midwifery and $A$ Set of Anatomical Tables. The plates in the latter work show the pelvis, external genitalia, the pregnant uterus at various months with its [3488] 
contents, twins, the process of normal labour with illustrations of various positions of the head; the application of the forceps in head and face delivery, the head impacted in the pelvis, with overlapping cranial bones, breech presentations; the application of forceps to the after-coming head; the head left in utero; and instruments with their mode of application. These plates are superior to any that had hitherto appeared, and Michaelis, the classical writer on the " narrow pelvis," says "they have perhaps achieved more in the spread of correct ideas of labour than all the books which have ever been written on the subject." William Smellie-the Master of British Midwifery-whom Fasbender in his G'eschichte der Geburtshiilfe styles " onẹ of the most important obstetricians of all times and countries," was born at Lanark in 1697. He studied medicine at Glasgow and began to practise in Lanark in 1720 . In 1735 he first learnt of the existence of the forceps, and, recognizing the importance of the instrument, in 1738 moved to London, started to teach midwifery there, and soon achiered great success both as a teacher and practitioner. In 1759 he returned to his native country, and spent the remainder of his life on his property at "Smellom" in preparing notes of his cases for publication, in which work he was aided by the literary ability of Tobias Smollett. He died in 1763, and was buried in the cemetery of St. Kentigern, Lanark.

The Management of Pregnancy and Normal Labour.

The importance of pre-maternity care of the pregnant woman was recognized in 1724 by Maubray, who gave it as one of the duties of the man-midwife or andro-boethogynist to watch the patient during pregnancy so as to prevent all "preternatural disasters"; and throughout the eighteenth century particular attention was paid to diet, hygiene, and evacuations of the patient. John Maubray is worthy of remembrance as the first teacher of practical midwifery and the first to suggest the building of a lying-in hospital in this country. He was the author of two books, The Female Physician, containing all the discases incident to that sex, in virgins, wives and widows; to which is added, The whole Art of New improved Midwifery, published in 1724; and Midwifery brought to Perfection by Manual Operation, published in 1725, in which he appears as a teacher of theoretical and practical midwifery to students, and appealed for the building of a hospital for lying-in women now more than two hundred years ago. His first book met with a " very kind reception," and is, in fact, both learned and entertaining. It is in this work, in the chapter on " deformed conceptions," that the remarkable description of the "sucker" occurs, which he had scen issue from the womb of a woman whom he was attending in labour on a vessel in the Zuyder Zee. The creature was stated to be so common amongst the seafaring people as that scarce one in three escaped this strange birth. It is described as being "likest of anything in shape and size to a Moodiwarp, having a hooked snout, fiery sparkling ejes, a long round neck, an acuminated short tail and an extraordinary agility of feet." In its crics and antics it had somewhat the semblance of a demon, "which indeed," says Maubray, "I took it for the first time I saw it, and that none of the better sort." 'Tlere is no documentary evidence that Maubray was other than an abstemious man, and the explanation of the phenomenon remains obscure. His unremitting efforts to establish a lying-in hospital never reached fruition; the project met with opposition, the fate of so many new undertakings. But his educational scheme was an entire success. His object was to give students the opportunity of obtaining their obstetrical knowledge in this country, instead of resorting to the barber-surgeons of Paris. He arranged to give two courses of twenty lessons each, which he considered sufficient to qualify any serious student, and, further, mado provision, at great expense to himself, of a sufficient number of pregnant women, upon whom the students might practise the touch and perform deliveries, everyone in his turn. In this way he flattered himself that in time he would stock not only London, but the whole of Great Britain, with a set of as good expert practitioners of midwifery as any other country whatsoever could boast of. John Maubray died in 1732, "justly esteemed as an honest publick-spirited man."
Sir Richard Manningham (1690-1759), who exposed the case of Mary Tofts, the " rabbit-breeder" of Godliman, established the first British lying-in wards in 1739.

As to the management of normal labour, the lying-in room of the period was hot, crowded, and ill ventilated, and the bed surrounded by heavy curtains in accordance with the universal custom of the time; and the patient was freely supplied with alcohol. It was only towards the end of the century that midwives were persuaded, mainly owing to the influence of Charles White and Leake, to admit the air and omit the alcohol. Charles White was the author of an important Treatise on the Management of Pregnancy and Lying-in Women, in which full and judicious instructions for the hygiene of pregnant and parturient women are given. White states that, by attention to the principles laid down, out of the whole number of patients whom he had delivered he had never lost one by "the puerperal, miliary, low nervous, putrid malignant, or milk fever.' He was a Manchester man, born in 1728; in the year 1752 he founded the Manchester Infirmary, where he held the position of chief surgeon for thirty-eight years. On his resignation of the post, owing to a disagreement with the management, he took a leading part in founding a "lyingin charity for attendance upon poor married women in their own homes," which developed into the St. Mary's Hospital, Manchester.

John Leake (1729-92) founded the New Westminster Lyingin Hospital in 1767. A severe and very fatal epidemic of puerperal fever which occurred in that hospital was the occasion of his making a close study of the disease. He published notes of all the cases and of several of the postmortem examinations. Ho opposed the view, then generally held, that the exudate on the intestines consisted of corrupted milk, and considered it to be "pure matter" due to inflammation of the uterus. "The disease," he says, "truly inflammatory in the beginning, may becone putrid by absorption of the purulent fluid which, like old leven, will taint the blood." He held that the season and air were concerned in the causation, and recommended that hospital beds should not be too numerous, that special delivery beds should bo instituted, the wards well ventilated, and the patient supplied with clean linen; further, that disinfection should be carried out by such means as the.smoke of burning wood, brimstone strewed on charcoal, and whitewashing. Leake was buried in the north cloister of Westminster Abbey.

In Harvey's time patients were delivered on the "threelegged stool," but in the eighteenth century they were delivered as a rule on the bed. The left lateral position was that usually adopted, although in special cases the patient was placed in the dorsal, reclining, sitting, or knecling position; the last was often adopted in cases of version, and, at times, for the application of the forceps. A great change for the better occurred in the conduct of normal labour when men-midwives came into practice. Harvey had inveighed against the "younger and more giddy and officious midwives who, lest they should become unskilful at their trade, do mightily bestirre themselves and provoko the expulsive faculty by mericinal potions," and Harvey's friend Willoughby complained of the "halings and stretchings" with which the midwives tormented their patients.

An important contribution to the management of labour was made by John Harvie in his recommendation of ahdominal manipulation and pressure for the delivery of the afterbirth. His directions are given in a little book on the preservation of the perineum and the delivery of the placenta, in which he says:

" as soon as the child is committed to the care of the nurse let the accoucheur apply his hand to the belly which is then very loose, and he will feel the contracting uterus, then, having placed tilo flat of his hand over it, let him by a light and gentle pressuris bring it downwards or towards the pubes, and he will feel thio uterus sensibly contracting and often will feel it so reduced in size as to be certain that the placenta is expelled. By this size as to be certain have anything to do afterwards, but to melp it through the os externum [that is, vulva], even if so help it through the os exte

Harvie was a teacher of midwifery at Wardour Street with Smellie, whom he succeeded.

It was especially Harvey's advocacy of gentleness and patience in the conduct of normal midwifery, in imitation 
of nature, which, followed by successive teachers-Smellie, Hunter, Denman-formed the guiding spirit of British practice for the next century and a half; and it was that conservative practice which impressed the great Viennese obstetrician, Böer, who, having studied abroad, came over to England and " learnt in France what Art, in England what Nature, could do." He introduced the English practice into the great lying-in hospital of Vienna, which became under his mastership the greatest lying-in institution in Europe. From 1784 to 1822, during the last thirty-three years of which Böer was at its head, the mortality from puerperal fever was $\mathbf{1 . 2 5}$ per cent. Under his successor the mortality rose in the maternity ward, where medical students were admitted, to 9.9 per cent., whereas in the wards attended by midwives (who did not practise dissection) the mortality sank from 5.5 per cent. to 3.3 per cent. It was this great difference which led Semmelweis (in 1842) to attribute puerperal fever to "putrifying animal substances" from without, and to order that the attendants should wash their hands with a solution of chloride of lime before attending midwifery cases.

Version.

Cephalic version was not much in favour with British obstetricians. Smellie abandoned it in favour of podalic version, which then became the favourite method of delivery in difficult cases. He was the first to apply the forceps to the after-coming head, and is also sometimes credited with being the first to deliver by what is described as the Mauriceau-Smellie-Veit method, but which would be more correctly called Giffard's method, since it was he who invented it. Giffard (a man-midwife and surgeon who died in 1731) was the author of a work entitled Cases in Miduifery, in which are given short accounts of 225 mostly difficult or dangerous cases attended by himself He describes the manœuvre thus:

"I clapped one hand flat upon the breast, and with the other taking hold above the shoulders drew towards me, but the head did not readily follow; I therefore passed my fingers up to the child's mouth, supporting the breast with my wrist and arm and putting one finger in the mouth and two others upon the cheeks, I pulled towards me, and at the same time drawing with my other hand above the shoulders, brought out the head."

Internal version was the operation usually performed; bimanual version was performed by Pugh (1754); external version had not yet appeared in British practice.

\section{Forceps.}

The forceps were invented by a member of the Chamberlen family, probably by Peter Chamberlen, the elder of that name-a barber-surgeon, distinguished obstetric practitioner, and physician to the Court, who died in 1631. The invention brought great credit to the Chamberlens, who were a family of obstetricians, and considered themselves justified in keeping it a secret for their own pecuniary advantage. The actual instruments used by them were discorered in 1813 in a secret space under the floor of a closet in Woodham Mortimer Hall, near Malden in Essex, formerly the residence of Dr. Peter Chamberlen, nephew of Peter the elder; they are now preserved in the library of the Royal Society of Medicine. Details of the invention, however, became known long before that date, and the merit of first publishing an account of the forceps belongs to Edmund Chapman, a surgeon and man-midwife who was in practice for several years at South Halstead in Essex before settling in London, where he became the second public teacher of midwifery. The account appeared in his Essay for the Improvement of Midwifery (1733), and two years later a second edition of the Essay gave an illustration of forceps of his own designing, in which the pin was omitted, he having accidentally discovered that the lock was equally firm without it. The first illustration of the Chamberlen forceps appeared in Giffard's work before mentioned, which was published in 1734 . Chapman states that the forceps were well known in 1733. The original form was straight, and the modification by the introduction of the pelvic curve appears to have been invented independently and at about the same time by Levret in France and in this country by Smellie and Benjamin Pugh. The latter, who practised as a surgeon in Essex, was the author of a Treatise on Midwifery (1754), in which are contained illustrations of the long and short curved forceps. Smellie became acquainted with the forceps (Dusé's) through Butter's Edinburgh Medical Essays (1735), and, finding them inefficient, set about to improve them. He contrived his short forceps, which proved the most efficient instrument of the time. By the invention of the lock which did away with the necessity of a movable axis for the blade, and by the later adoption of the pelvic curve, he produced an instrument which has not been essentially modified or improved by succeeding obstetricians. Although Smellie took so prominent a part in the development of the forceps, he was restrained in the use of them, for he states that " only 10 out of 1,000 labours required instrumental delivery."

\section{Fillet and Lever.}

The fillet was used occasionally by the eighteenth century obstetricians, and ingenious contrivances were invented for passing the traction-cord over the child's head. Chapman must have had some liking for the instrument, since he kept his method of using it secret when he published the account of the forceps. But after Smellie had pointed out that it was liable to tear the scalp of the child, and Pugh had expressed the opinion that " all kinds of fillets were but idle things," it was generally abandoned by skilled practitioners.

Not so the lever. This instrument underwent many modifications from the original model of Roonhuysen, one of the best designs being that of Lowder, a well known lecturer on midwifery in St. Saviour's Churchyard, Southwark, and graduate of the University of Aberdeen (1775). Several manuscript copies of Lowder's. lectures are in existence, and show hin to have been a judicious and interesting teacher and an experienced practical obstetrician. $\mathrm{He}$ gives an excellent account of the pelvis and its measurements, and discusses the possibility of detecting pelvic deformity by general inspection, stating that deformity may be suspected if the patient has had rickets or has a great falling in of the back and projection of the nates; " but," he adds, " here we must be certain that the appearance of the falling in of the back and projection of the nates is not owing to the fashion the ladies have nowadays of wearing cork rumps." Some claimed that Lowder's lever was equal or superior to the forceps, but it is clear that they must have used the instrument to alter the position of the child's head rather than to extract it. An ingenious modification was Aitken's " living-lever," in which the curve of the blade could be increased after it had been introduced, so as to form a sharply curved surface by which to make traction on the occiput and thus convert a "face" into a " vertex" presentation.

The Treatment of Contracted Pelvis.

The conservative principles which underlay the practice of Harvey, Smellie, Hunter, and Denman led to difficulties when applied to severe degrees of pelvic contraction. Minor degrees allowed version or the use of the lever or forceps, and it is surprising to read how seldom any other method was required. It is to be regretted that we have no exact statistics of the mortality of cases so treated; but the rarity of cases in which one or other of these operations was not possible suggests that cases of severe pelvic contraction were less often met with than at the present day. In order to get over the difficulty in severe cases British obstetricians proposed to diminish the size of the passenger, either by the induction of premature labour (first carried out by Dr. Macaulay) or by reducing the size of the child by restricted diet (first carried out by Lucas of Leeds in 1794).

Symphyseotomy, which was performed for the first time in England by Welchman in 1782, has never gained general favour among British obstetricians. In the eighteenth century it was condemned by the Hunters and Denman, and only favoured by Leake and Aitken; the latter in 1785 proposed his " new pelvitomy," the precursor of the modern pubiotomy, in which the rami of the pubis and ischium were to be sawn through on each side "so that the anterior segment of the pelvis becomes movable and yields to the pressure of the child so as to allow delivery." John Aitken was a surgeon and man-midwife who practised in Edinburgh, 
and founded, in 1784 , a lying-in hospital in which about 100 women were delivered annually.

Caesarean section in the eighteenth century was almost always fatal to the mother. In Ireland it had once succeeded, and then it was performed by an ignorant midwife, Mary Donally, in 1738-39; in England the first successful operation was performed by Barlotv of Bolton in 1793, and in that case the child did not survive. The operation was stigmatized by Ould as a "detestable, barbarous, illegal piece of inhumanity." Although Smellie and Burton in the middle of the century, and Hamilton and Denman at the end, had accepted the operation for cases of extreme pelvic contraction, Osborn denied that either Caesarean section or symphyseotomy was ever a justifiable operation. He described cases of the severest degree of pelvic contraction in which he had been able to deliver by means of craniotomy, and, recognizing that the recovery of the mother depended on its being performed before she became exhausted, he extended the indications to cases which perhaps might have been delivered by forceps, and thereby attracted a good deal of censure, especially from foreign cbstetricians, as the enthusiastic advocate of mutilating operations. In favour of Osborn it must be remembered that Caesarean section and symphyseotomy were at that time almost uniformly fatal, that British obstetricians have always regarded the child's life as less valuable than the mother's, and that fatal results to the mother from craniotomy depend almost entirely on its being performed too late. William Osborn, a friend and fellow lecturer of Denman, was born in Iondon in 1736. In 1770 he joined Denman in founding a school of midwifery, and became one of the most successfill teachers, more than twelve hundred practitioners of midwifery having attended his lectures.

For the performance of craniotomy cither a guarded knife or scissors was employed, of which Smellie's scissorsperforator was the most practical. In the extraction of the child's head after perforation the crochet was mostly usedat first the straight instrument, afterwards the curved crochet, and finally (by Smellie) the double crochet. Opinions differed as to whether the instrument should be fixed inside or outside the skull. The forceps were also used for extracting the head (Smellie), or the forceps with a crochet at the end of the blade (Pugh).

Haemorrhages and Convulsions.

Tho haemorrhages most frequently recorded at this period were of the ante-partum variety, due to separation of the placenta either normally situated or praevia. Giffard was the first British author to point out the occurrence of true placenta praevia, as distinguished from prolapse of the organ. The treatment was sometimes rupture of the membranes, but usually podalic version. Postpartum haemorrhage was treated mostly by sedatives and tonics; but sometimes by local styptics, the disadvantages of which were recognized. Cold applications were also employed. There is no record of the employment of manual compression of the uterus. Several cases of haemorrhage due to inversion of the uterus are described, in some of which recovery followed the reduction of the inversion. A few cases of rupture of the uterus are mentioned; one of these is illustrated by Denman in a fine plate.

Convulsions were treated by bleeding, blistering, opiates (extract. or tinct. thebaic.), hot baths, and clysters. The temporal artery or jugular vein was of ten recommended as the vessel to be opened.

Ectopic Gestation and Hydatidiform Mole.

Interesting cases of these conditions were published ty Giffard, with illustrations. The ovum of the ectopic gestation was passed by the rectum, to which the sac adhered. The case of hydatidiform mole terminated fatally a year after the delivery, a tumour being found in the uterus, which was thought to be the placenta, but was probably a chorion-epithelioma.

Summary Review of the Period.

It may be said that during the one hundred and fifty years after Harvey published his De Generatione Animalium a great advance was made in the science and art of midwifery. This was chiefly due to the introduction of male practitioners, many of whom were men of learning and devoted to anatomy, the groundwork of obstetrics. The institution of lying-in hospitals by these male practitioners had an important influence in promoting teaching and research. The general introduction of the use of the forceps placed in their hands means, previously unknown, of delivering women, and by its results gradually overcame the opposition of the midwives, surgeons, and physicians to the new class of men-midwives. The action of the College of Physicians in instituting a special diploma of "Licentiate in Midwifery" was not without influence in improving the status of those practising midwifery, although it ceased to be granted in the year 1800 .

The characteristic of British midwifery at this period was conservatism. Although by somo practitioners carried to excess, it led to laudable attempts, exclusively British, to avoid the operations of craniotomy which sacrificed the child, and of Caesarean section and symphyseotomy which so often proved fatal to the mother.

The forceps were sometimes used unnecessarily then, as now; but the abuse of operative methods of delivery is much greater at the present time, and no better correctivo of that abuse could be prescribed than a study of the careful records of the British obstetricians of the seventeenth and eighteenth centuries, showing the resources of that " perfect operatrix" Nature in effecting delivery.

\section{CHEMICAL CHANGES ACCOMPANYING MUSCULAR ACTIVITY.*}

BY

THOMAS HUGH MILROY, M.D., F.R.S.ED.,

Dunville Professor of Physiology, Queen's University, Belfast.

As the subject open for discussion deals with the chemical changes associated with muscular activity it is necessary in the first place to consider the nature of the constituents which probably play a part in the energy changes associated with activity. These chemical changes are mainly concerned with the transformations of glycogen. As the transformations are brought about by the action of enzymes within the muscle, there must at all times be present in muscle evidence of enzymatic changes having beon in progress, and thus it is to be expected that the products of ferment action should be present in varying amounts, the variations depending upon the conditions under which the muscle has been placed. Thus when muscle is removed from the body and the conditions are such that the removal of the products of ferment action cannot be effected, eithei by oxidation, owing to the predominantly anaerobic conditions existing, or by diffusion away from the seat of formation, then we should expect to obtain evidence of the accumulation of the products of degradation of the glycogen. The extent of the breakdown process will be determined by the activity of the ferments under the physical conditions existing, by the inhibiting effect on the enzymes of the products of their activity, and, in the case of acid production, by the reaction alterations in the medium. It is therefore evident that in intact, and still more in minced muscle tissue, living or dying under anaerobic conditions, the enzymatic products of the anaerobic degradation of glycogen should increasc. Thio relative amounts of the glycogen and the products of enzymatic action on this carboliydrate in muscle which has been quickly removed from the body, and in which ferment action is checked by such a process as freezing, will give some information as regards the equilibrium established normally between the mother substance and the products of its enzymatic disintegration.

On examination of such muscle tissue it is evident that there are present, in addition to glycogen, substances which have been derived from it-namely, intermediate polysaccharides, hexoses, phosphoric acid esters of the hexoses, and lactic acid, not to speak of possible immediate

* A paper introducing a discussion in the Section of Physiology and Biochemistry at the Annual Meeting of the British Medical Association, Edinburgh, 1927 . 